\title{
Facilitated Transport of Lysine Acetylsalicylate Through Supported Liquid Membrane Using Methyl Cholate as Carrier: Parameters and Mechanism
}

\author{
Oussama Kamal ${ }^{1,2, ~}{ }^{*}$, Tarik Eljaddi ${ }^{1}$, Habib Mouadili ${ }^{1}$, El Houssaine EL Atmani ${ }^{1}$, Laurent Lebrun ${ }^{2}$, \\ Miloudi Hlaïbi ${ }^{1,2}$ \\ ${ }^{1}$ Laboratory of Materials Engineering for the Environment and Valuation, Faculty of Sciences Aïn Chock, University Hassan II, Casablanca, \\ Morocco \\ ${ }^{2}$ Laboratory of Polymeres Biopolymeres Surfaces, Faculty des Sciences, University of Rouen, Mont-Saint-Aignan, France
}

\section{Email address:}

kamaloussama@hotmail.fr (O. Kamal)

${ }^{*}$ Corresponding author

\section{To cite this article:}

Oussama Kamal, Tarik Eljaddi, Habib Mouadili, El Houssaine EL Atmani, Laurent Lebrun, Miloudi Hlaïbi. Facilitated Transport of Lysine Acetylsalicylate Through Supported Liquid Membrane Using Methyl Cholate as Carrier: Parameters and Mechanism. American Journal of Chemical Engineering. Vol. 5, No. 4, 2017, pp. 49-55. doi: 10.11648/j.ajche.20170504.11

Received: April 15, 2017; Accepted: May 5, 2017; Published: June 21, 2017

\begin{abstract}
Transport of lysine acetylsalicylate (LAS) through supported liquid membrane was investigated using methyl cholate (MC) as extractive agent. Kinetic and thermodynamic models were developed, based on the interaction of the substrate LAS with the extractive agent T, and the diffusion of the formed entity (TS) through the membrane. The experimental results verify the models and enable the determination of macroscopic parameters (permeabilities $(P)$ and initial fluxes $\left(J_{0}\right)$ ), as well as microscopic parameters (association constants $\left(K_{\text {ass }}\right)$, and apparent diffusion coefficients $\left(D^{*}\right)$ ), relating to formed entity (TS) and its diffusion through the membrane organic phase. Parameters such as initial concentration of the substrate in the feed phase, $\mathrm{pH}$ of the feed and stripping phases and temperature of the extraction medium were studied. The results obtain indicate that the mechanism of the migration of LAS through the membrane organic phase cannot be a pure diffusion movement but it takes place by successive jumps from one site to another of the extractive agent, via interaction reactions with LAS.
\end{abstract}

Keywords: Facilitated Transport, Supported Liquid Membranes, Permeability, Flux, Activation Parameters

\section{Introduction}

Lysine acetylsalicylate (LAS) is a water soluble derivative of acetylsalicylic acid. This compound belongs to the group of nonsteroidal anti-inflammatory drugs. LAS is the active ingredient of aspegic an international brand of aspirin, which is widely used to treat mild to moderate pain, inflammation and fever. In low doses, LAS is an effective blood thinner and is used to prevent heart problems and stroke. LAS mechanism of action is based on the irreversible inhibition of cyclooxygenase enzymes involved in the synthesis of prostaglandins. LAS also inhibits platelet aggregation by blocking the platelet thromboxane A2 synthesis [1].

The presence of pharmaceutical active ingredients in the environment especially in the surface water and groundwater through leaching is of concern due to their toxic effects potentially harming the aquatic organisms as well as triggering long term adverse human health effects. Thereby, effective monitoring and treatment of wastewaters and water supply sources to ensure safety and quality of water that is discharged to the environment or the water used for drinking and for recreational purposes, is of paramount importance for the environment and human health [2]. Many applications for pharmaceutical active ingredients removal from wastewater are available including ion exchange, adsorption, flocculation and biological degradation [3,4]. Membrane technology has attracted much research for industrial wastewater treatment. Liquid membrane (LM) is a highly integrated separation technique which combines extraction and stripping processes in one step. The advantages of LM include the ease of scaleup, high selectivity, low consumption of extractant and 
absence of flooding. Therefore, LM is considered as a promising separation method for wastewater treatment $[5,6]$. Among the LM technologies that have received growing attention are the supported liquid membranes (SLMs) [7]. They consist of an extractant dissolved in an organic solvent and immobilized in the pores of a polymer support by capillary forces.

SLMs have been widely applied to extract metal ions species [8, 9, 10, 11], and organic compounds [12, 13, 14] from aqueous solutions. A number of studies have recently been conducted which focus on the extraction and removal of some pharmaceutical active ingredients using SLMs as an extraction technique. Indeed, Kawasakia et al. [15] studied the extraction of an antibiotic "Erythromycin A" from a diluted alkaline aqueous solution using a SLM containing 1decanol as carrier. Also, Ishizu et al. [16] used a SLM containing di-n-octylamine as carrier diluted in toluene or mesitylene as organic phase to achieve the extraction of "compactin" active ingredient from a diluted aqueous solution. Kouki et al. [17] studied the feasibility of the extraction of salicylic acid from acidic aqueous solution using a SLM containing aliquat-336 ionic liquid as carrier diluted in 2-octanol as organic phase.

In this paper we studied the extraction of LAS active ingredient from acidic aqueous solutions through a SLM containing a new amphiphilic carrier Methyl Cholate MC. The incidence of several parameters such as $\mathrm{pH}$ of feed and striping solutions, initial concentration of the substrate LAS, concentration of the carrier agent in the membrane and the temperature of the extraction medium were studied.

\section{Material and Methods}

\subsection{Reagents and Membranes}

The LAS active ingredient was obtained commercially. MC extractant with nominal purity of greater than 98.0 mass \%, was purchased from Alpha Aesar. Hydrochloric acid, toluene and sodium hydroxide were analytical grade and purchased from Sigma Aldrich. A hydrophobic polyvinylidene difluoride (PVDF) membrane (HVLP090050, Millipore) was used as supporting membrane. The membrane nominal pore diameter, porosity and thickness were $0.45 \mu \mathrm{m}$, $69 \%$ and $100 \mu \mathrm{m}$, respectively.

Feed solutions were prepared by dissolving LAS in deionized water. The $\mathrm{pH}$ of these solutions was maintained at different values ranging from 3 to 5 . Deionized water solutions with the same $\mathrm{pH}$ ranging values were used as stripping solutions. All reagents of analytical grade or higher were used without further purification.

\subsection{Transport Experiments}

The flat-sheet supported liquid membrane was prepared at room temperature by impregnating the micro-porous PVDF film with a solution containing the MC carrier diluted in toluene as organic phase for 6 hours. The SLM was then placed in the middle of a two compartment permeation cell represented by the diagram in Figure 1. This cell consists of two glass compartments, separated by the micro porous membrane $(\mathrm{M})$. The feed and the stripping solutions $(75 \mathrm{~mL}$ each) were placed in each compartment of the cell. The cell is immersed in a thermostated bath (TB). Both aqueous feed and stripping solutions were magnetically stirred at $600 \mathrm{rpm}$ at $25 \pm 1{ }^{\circ} \mathrm{C}$ using a Variomag Bioblock multi stirrer (MS) to avoid concentration polarization conditions at the membrane interfaces and in the bulk of the solutions. The exposed membrane area was $9.61 \mathrm{~cm}^{2}$. Several samples in the stripping phase in known time intervals were taken to determine LAS concentration according to the analytical method described below.

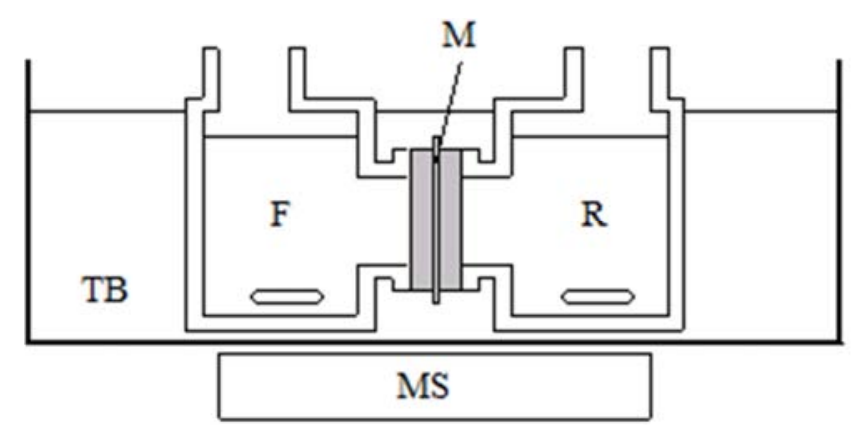

Figure 1. Scheme of the transport cell.

\subsection{Analytical Method}

Small aliquots from the stripping solutions were withdrawn at known time intervals. These samples were diluted in an excess of sodium hydroxide solution to perform the complete hydrolysis of LAS into salicylate ions which has a maximum band of absorption at a wavelength of 300 $\mathrm{nm}$ [18]. A standard Helios $\gamma$ UV-visible spectrometer was used to analyze the LAS samples concentrations and a Hanna 210 microprocessor $\mathrm{pH}-\mathrm{meter}$, equipped with a combined glass electrode and calibrated with commercial buffers $(\mathrm{pH}$ 4.00 and 7.00) was used for $\mathrm{pH}$ measurements.

\section{Kinetic and Thermodynamic Models to Calculate the Macroscopic, Microscopic, and Activation Parameters}

Recent studies have shown that the macroscopic parameters, permeability $P$ and initial flux $J_{0}$, are calculated from the following relationships [19].

$$
\begin{gathered}
P\left(t-t_{L}\right)=\frac{l V}{2 S} \ln \left(\frac{C_{0}}{C_{0}-2 C_{r}}\right) \\
P=a \frac{l V}{2 S} \\
J_{0}=P \frac{C_{0}}{l}
\end{gathered}
$$

$a$, slope of the linear plot of $-\ln \left(C_{0}-2 C_{r}\right)$ as a function of time. 
$l$, the membrane thickness.

$S$, the membrane area in contact with the aqueous solutions.

$V$, the receiving phase volume.

Similarly, these same studies have shown that for this facilitated extraction process, a thermodynamic model was developed to determine the microscopic parameters $K_{\text {ass }}$ and $D^{*}$ according to the following relationships:

$$
\begin{gathered}
1 / J_{0}=\frac{l}{D^{*}}\left(\frac{1}{\left[T_{0}\right] K_{a s s} C_{0}}+\frac{1}{\left[T_{0}\right]}\right) \\
K_{\text {ass }}=\frac{\operatorname{intercept}(O O)}{\operatorname{slope}(p)} \text { and } D^{*}=\frac{l}{O O\left[T_{0}\right]}
\end{gathered}
$$

With $\mathrm{p}$ and $O O$, the slope and intercept experimental values of the straight line $1 / J_{0}=f\left(1 / C_{0}\right)$ and $[T]_{0}$ the fixed total concentration of the extractive agent.

Studies related to the facilitated extraction process of ions across membranes, [20,21] indicate that the initial flux is related to temperature factor by Arrhenius law, according to the following relationship:

$$
J_{i}(T)=A_{i} \exp \left(-\frac{E_{a}}{R T}\right)
$$

$A_{j}$ is a constant (pre-exponential factor), and $E_{a}$ is the transition state activation energy for the associationdissociation reaction of entity (TS) at the membrane interfaces and in the membrane organic phase, during the migration of the substrate through the membrane, which is the rate-determining step relative to the apparent diffusion of the entity (TS). After linearization, we get the following equation:

$$
\ln J_{i}=-\frac{E_{a}}{R T}+\ln \left(A_{j}\right)
$$

Thus, the terms of activation energy $\left(E_{a}\right)$ and preexponential factor $\left(A_{j}\right)$ are determined from the slope and intercept for the linear function $\operatorname{Ln}\left(J_{i}\right)=f(1 / T)$. According to the activated complex theory $[22,23]$ we can calculate the activation parameters, enthalpy $\Delta H^{\#}$ and entropy $\Delta S^{\#}$, according to the following expressions:

$$
\begin{gathered}
\Delta \mathrm{H}^{\#}=E_{a}-2500\left(\mathrm{~J} \cdot \mathrm{mol}^{-1}\right) \\
\Delta \mathrm{S}^{\#}=R\left(\ln A_{j}-30.46\right)\left(\mathrm{J} \cdot \mathrm{K}^{-1} \cdot \mathrm{mol}^{-1}\right) \text { at } 298 \mathrm{~K}
\end{gathered}
$$

\section{Results and Discussion}

\subsection{Effect of the Substrate Initial Concentration and the pH of the Feed and Stripping Solutions}

To study the influence of the substrate initial concentration and the $\mathrm{pH}$ of the feed and stripping solutions on the facilitated extraction of LAS, we prepared three SLMs containing each $0.01 \mathrm{M}$ of MC extractive agent. Each SLM was used under the same experimental conditions; the concentration of LAS compound and the $\mathrm{pH}$ of the feed and stripping solutions were varied respectively in the range of
$0.1000 \mathrm{M}$ to $0.0125 \mathrm{M}$ and 3 to 5 , toluene was used as organic phase and all experiments were carried out at $298 \mathrm{~K}$. The straight lines of the kinetic model obtained are represented by the graphs in Figure 2 and the obtained values of the permeabilities $P$ and fluxes $J_{0}$ of each SLM used are summarized in Table 1.

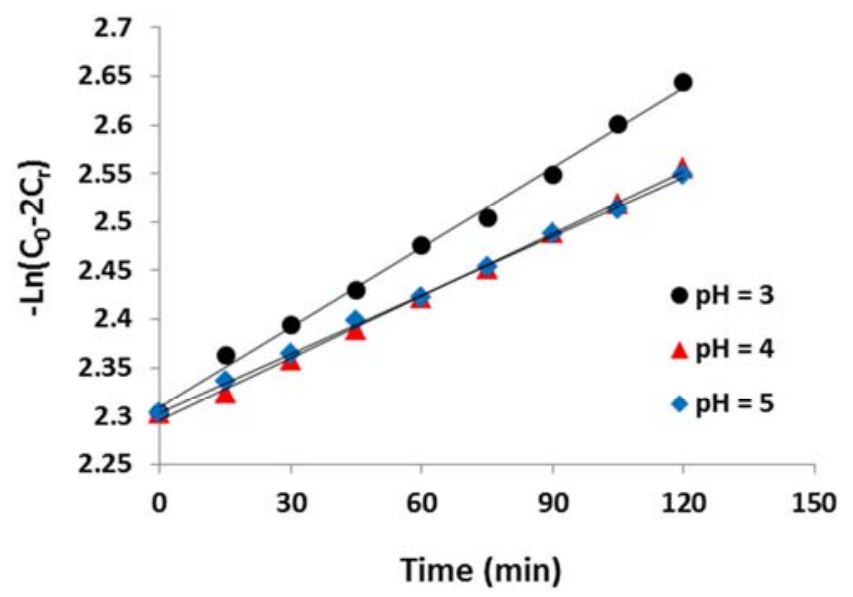

Figure 2. Plots of $-\ln \left(C_{0}-2 C_{r}\right)$ vs time $t$ for the facilitated extraction of LAS through the $S L M-M C .[M C]=0.01 \mathrm{M}$, [LAS] $=0.1 \mathrm{M}, \mathrm{T}=298 \mathrm{~K}$.

Table 1. Influence of the $\mathrm{pH}$ of feed and stripping solutions on the evolution of the macroscopic parameters $P, J_{0}$ for the facilitated extraction of LAS.T= $298 \mathrm{~K},[\mathrm{MC}]=0.01 \mathrm{M}$.

\begin{tabular}{llll}
\hline $\begin{array}{l}\text { pH (feed and } \\
\text { stripping) }\end{array}$ & LAS $(\mathbf{M})$ & $\begin{array}{l}\mathbf{P} \times \mathbf{1 0}^{\mathbf{7}} \\
\left(\mathbf{c m}^{\mathbf{2}} \cdot \mathbf{s}^{-\mathbf{1}}\right)\end{array}$ & $\begin{array}{l}\mathbf{J}_{\mathbf{0}} \mathbf{x} \mathbf{1 0} \\
\left(\mathbf{m m o l} \cdot \mathbf{s}^{\mathbf{- 1}} \cdot \mathbf{c m}^{\mathbf{2}}\right)\end{array}$ \\
\hline \multirow{3}{*}{3} & 0.1000 & 17.57 & 1.75 \\
& 0.0500 & 20.18 & 1.01 \\
& 0.0250 & 22.78 & 0.56 \\
& 0.0125 & 26.69 & 0.33 \\
\hline \multirow{3}{*}{4} & 0.1000 & 13.67 & 1.36 \\
& 0.0500 & 16.27 & 1.81 \\
& 0.0250 & 20.83 & 0.52 \\
& 0.0125 & 22.78 & 0.28 \\
\hline \multirow{3}{*}{5} & 0.1000 & 13.02 & 1.30 \\
& 0.0500 & 18.22 & 0.91 \\
& 0.0250 & 20.83 & 0.52 \\
& 0.0125 & 22.13 & 0.27 \\
\hline
\end{tabular}

The experimental results indicate that the permeabilities $P$ of the used SLMs-MC vary inversely with the initial concentration $C_{0}$ of the LAS, and an increase in $C_{0}$ results in a decrease in permeabilities, however, the initial flux values $J_{0}$ for this compound for each of the studied SLMs-MC, increase as the initial concentration $C_{0}$ of LAS increases. These evolutions of the macroscopic parameters on this facilitated extraction phenomenon was indicated by Touaj et al. [24] for the transport of some disaccharide sugars and by Hor et al. [25] for the facilitated extraction of $\mathrm{VO}_{2}{ }^{+}$ions. Also the results show clearly that the values of permeabilities $P$ and fluxes $J_{0}$ increase as the $p H$ of the feed and stripping solutions decreases, hence the acidity of the extraction medium increase. 


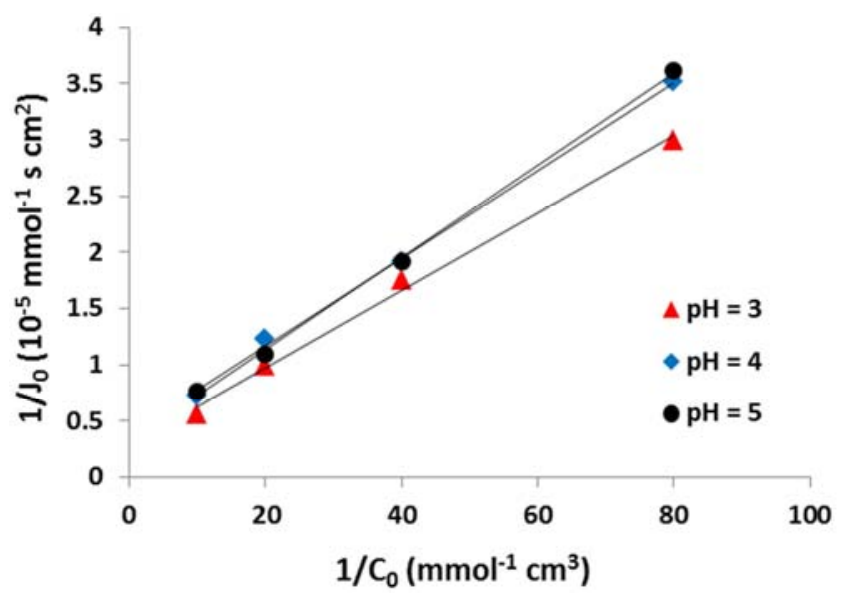

Figure 3. Plots of $1 / J_{0}$ vs. $1 / C_{0}$ for the facilitated extraction of LAS through the $S L M-M C$, $[M C]=0.01 M, T=298 \mathrm{~K}$.

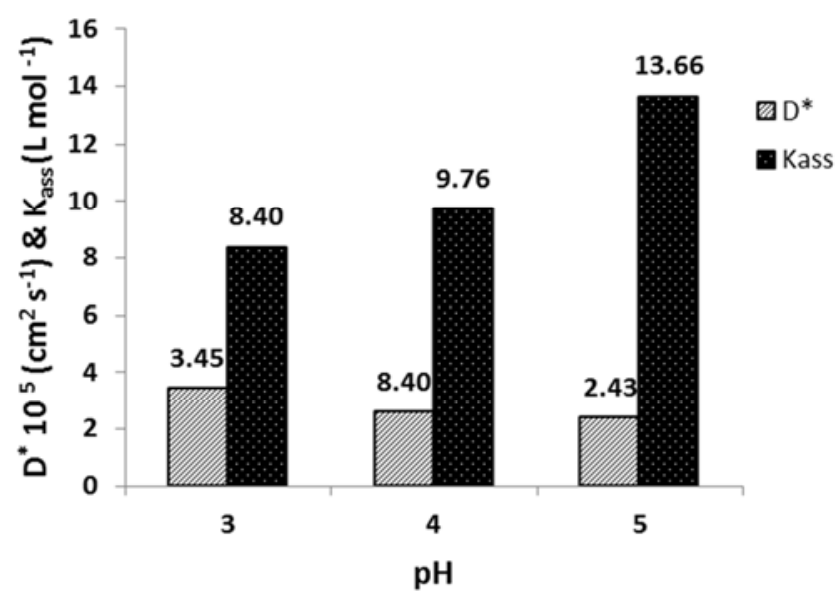

Figure 4. Evolution of the parameters $D^{*}$ and $K_{\text {ass }}$ for the facilitated extraction of $L A S$, depending on the $\mathrm{pH}$ of the feed and stripping solutions.

The obtained values of the microscopic parameters Kass and $D^{*}$ (Figure 4) clearly indicate a clear influence of the $\mathrm{pH}$ values on those microscopic parameters and on the performances of the studied membranes. The reverse evolution of $K_{a s s}$ and $D^{*}$ parameters confirms the interaction between LAS and the MC extractive agent with a formation of an entity (ST) that migrates through the organic phase of the membrane.

\subsection{Effect of the Temperature Factor}

To better understand the facilitated extraction mechanism of LAS by the SLMs-MC used, explain the experimental results and determine the activation parameters, the influence of temperature factor on the evolution of the macroscopic $P$, $J_{0}$ and microscopic $D^{*}, K_{\text {ass }}$ parameters was examined by performing experiments for the facilitated extraction of LAS under the similar experimental conditions. The $\mathrm{pH}$ of the feed and stripping solutions was maintained at 3 , concentration of the MC extractive agent at $0.01 \mathrm{M}$ and $C_{0}$ concentrations of LAS ranged from $0.1000 \mathrm{M}$ to $0.0125 \mathrm{M}$. All the experiments were carried out at three different temperatures 298, 303 and 308 K. Graphs in Figure 5 represent the straight lines related to the evolution of the term $-\operatorname{Ln}\left(C_{0}-2 C_{r}\right)$ with time provided by kinetic model, for the different studied temperatures. The obtain values of the macroscopic parameters $P, J_{0}$ are summarized in Table 2.

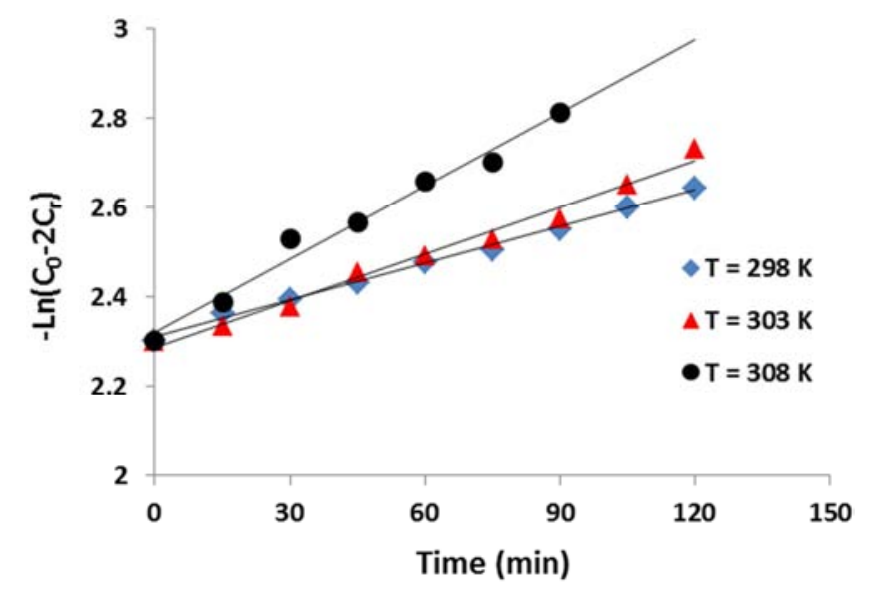

Figure 5. Plots of $-\ln \left(C_{0}-2 C_{r}\right)$ vs time t for the facilitated extraction of LAS through the $S L M-M C$. $[M C]=0.01 \mathrm{M},[L A S]=0.10 \mathrm{M}, \mathrm{pH}=3$.

Table 2. Temperature factor Influence on the evolution of the macroscopic parameters $P, J_{0}$ for the facilitated extraction of $L A S$. $p H=3,[M C]=0.01$ M.

\begin{tabular}{llll}
\hline $\begin{array}{l}\text { T(K) (feed and } \\
\text { stripping phases) }\end{array}$ & LAS $(\mathbf{M})$ & $\begin{array}{l}\mathbf{P} \times \mathbf{~ 1 0}^{\mathbf{7}} \\
\left(\mathbf{c m}^{2} \cdot \mathbf{s}^{-1}\right)\end{array}$ & $\begin{array}{l}\mathbf{J}_{\mathbf{0}} \mathbf{x} \mathbf{1 0}^{\mathbf{5}} \\
\left(\mathbf{m m o l} \cdot \mathbf{s}^{-1} \cdot \mathbf{c m}^{2}\right)\end{array}$ \\
\hline \multirow{3}{*}{298} & 0.1000 & 17.75 & 1.75 \\
& 0.0500 & 20.18 & 1.01 \\
& 0.0250 & 22.78 & 0.56 \\
& 0.0125 & 26.69 & 0.33 \\
\hline 303 & 0.1000 & 22.78 & 2.27 \\
& 0.0500 & 25.39 & 1.26 \\
& 0.0250 & 28.64 & 0.71 \\
& 0.0125 & 32.55 & 0.40 \\
\hline \multirow{3}{*}{308} & 0.1000 & 33.85 & 3.38 \\
& 0.0500 & 37.76 & 1.88 \\
& 0.0250 & 41.01 & 1.02 \\
& 0.0125 & 44.92 & 0.56 \\
\hline
\end{tabular}

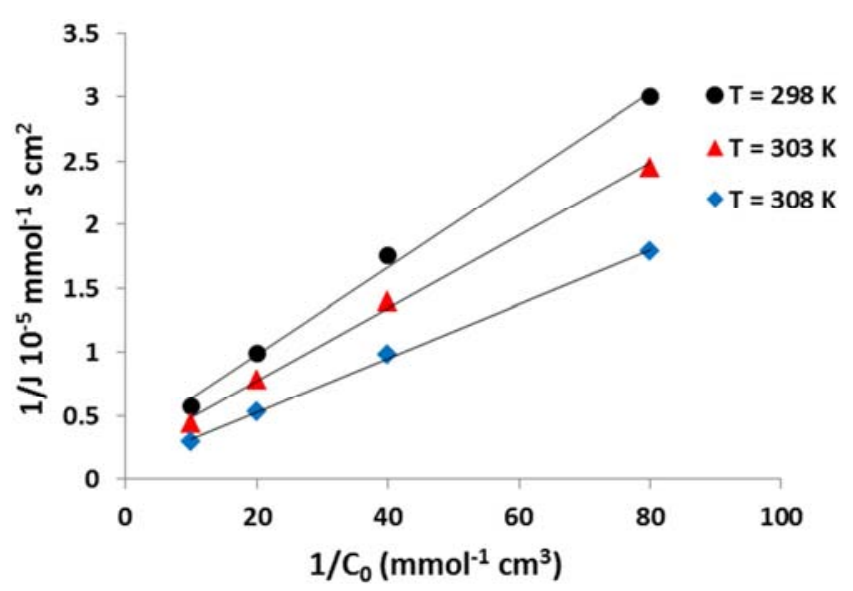

Figure 6. Plots of $1 / J_{0}$ vs. $1 / C_{0}$ for the facilitated extraction of LAS through the $S L M-C M,[M C]=0.01 M, p H=3$. 


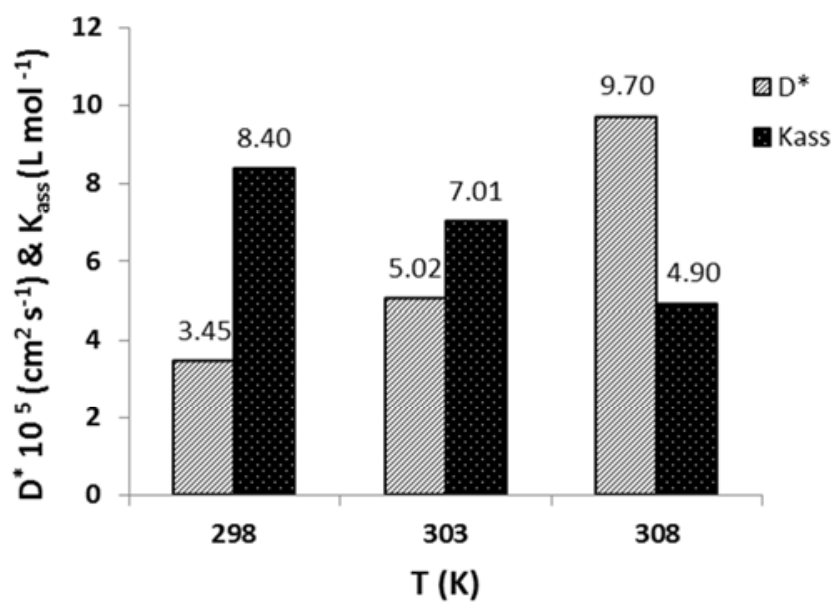

Figure 7. Evolution of the parameters $D^{*}$ and $K_{\text {ass }}$ for the facilitated extraction of $L A S$, depending on the temperature of the feed and stripping solutions.

These results confirm that the permeability $P$ and the initial flux $J_{0}$ parameters vary inversely, and with the initial concentration $C_{0}$ of LAS. They also indicate clear influence of the temperature factor. In fact, permeability $P$ and the initial flux $J_{0}$ increase with increasing temperature of the extraction medium, and therefore these lead to an increase in the membrane performances. To confirm the previous results and to study temperature factor influence on the evolution of microscopic parameters $D^{*}$ and $K_{\text {ass }}$, we traced the Lineweaver-Burk lines, $1 / J_{0}=\mathrm{f}\left(1 / C_{0}\right)$. The obtained line segments are represented by the graphs in Figure 6 and the evolution of the microscopic parameters is represented in Figure 7.

The obtained results confirm the inverse evolution of the microscopic parameters, and the temperature factor influence. In fact, an increase in the temperature causes a decrease in the value of $K_{a s s}$, and an increase in the value of the coefficient $D^{*}$, and therefore an improvement of the membrane performance. For the three studied membranes, the results indicate a clear influence of temperature factor on the evolution of $K_{a s s}$ and $D^{*}$ parameters, and an increase in temperature results in a weak association of substrate LAS with the extractive agent MC, therefore a good substrate diffusion through the membrane.

\subsection{Thermodynamic Parameters $E a, \Delta H^{\ddagger}$ and $\Delta S^{\neq}$.}

To examine the influence of energetic and associative terms on the mechanism for the facilitated extraction of LAS, we plotted the function $\operatorname{Ln}\left(J_{\text {omoy }}\right)=\mathrm{f}(1 / T)$ provided by Arrhenius relationship. For the adopted SLMs, the line segments obtained at the studied temperatures are represented by the graph in Figure 8 .

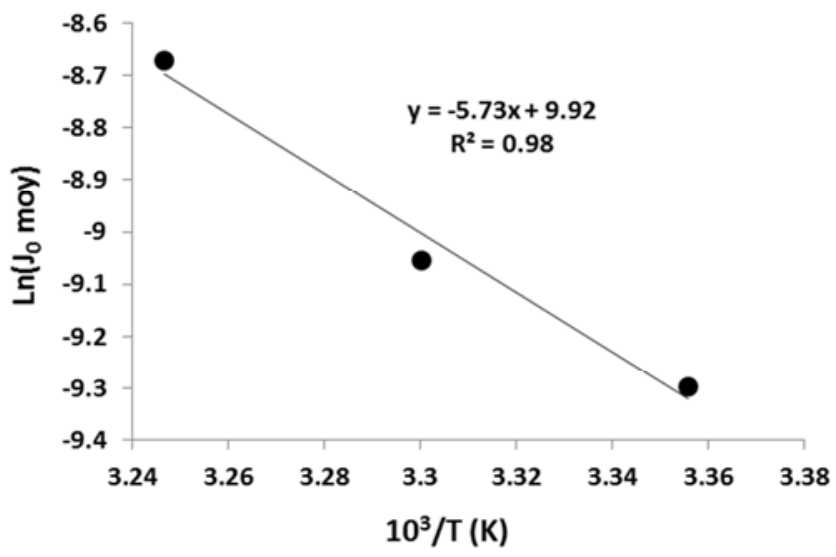

Figure 8. The representation of $\operatorname{Ln}\left(J_{\text {omoy }}\right)=f(1 / T)$ function for the facilitated extraction of LAS by the SLMS-MC membranes.

Table 3. Activation parameters for the facilitated extraction of LAS through the studied SLMs-MC. [MC] $=0.01 M, p H=3$.

\begin{tabular}{llll}
\hline $\mathbf{E}_{\mathbf{a}}\left(\mathbf{k J} \cdot \mathbf{m o l}^{-\mathbf{1}}\right)$ & $\begin{array}{l}\mathbf{1 0}^{\mathbf{4}} \mathbf{A}_{\mathbf{j}} \\
\left(\mathbf{m o l}^{-1} \cdot \mathbf{s}^{-\mathbf{1}} \cdot \mathbf{m}^{\mathbf{2}}\right)\end{array}$ & $\begin{array}{l}\Delta \mathbf{S}^{\#} \\
\left(\mathbf{J} \cdot \mathbf{K}^{-\mathbf{1}} \cdot \mathbf{m o l}^{-\mathbf{1}}\right)\end{array}$ & $\begin{array}{l}\Delta \mathbf{H}^{\#} \\
\left(\mathbf{k J} \cdot \mathbf{m o l}^{-\mathbf{1}}\right)\end{array}$ \\
\hline 47.64 & 2.03 & -170.68 & 45.16 \\
\hline
\end{tabular}

The value found for the activation energy $E a$ clearly indicates that the transition states related to the associationdissociation reactions of the LAS substrate with the extractive agent $\mathrm{MC}$ require small amounts of energy. The high value of the steric factor $A j$ and negative value of the activation entropy show that those transition states are highly ordered states which confirm the true association between LAS and the MC extractive agent.

Moreover, recent studies [26, 22] confirm the previous results found which indicate that the substrate movement across each studied membranes cannot be a pure diffusion movement (way $A$ ), but it takes place by successive jumps from one site to an another of used extractive agent, via interaction reactions of LAS with the extractive agent $\mathrm{MC}$ according to (way $B$ ) indicated by the diagram in Figure 9.

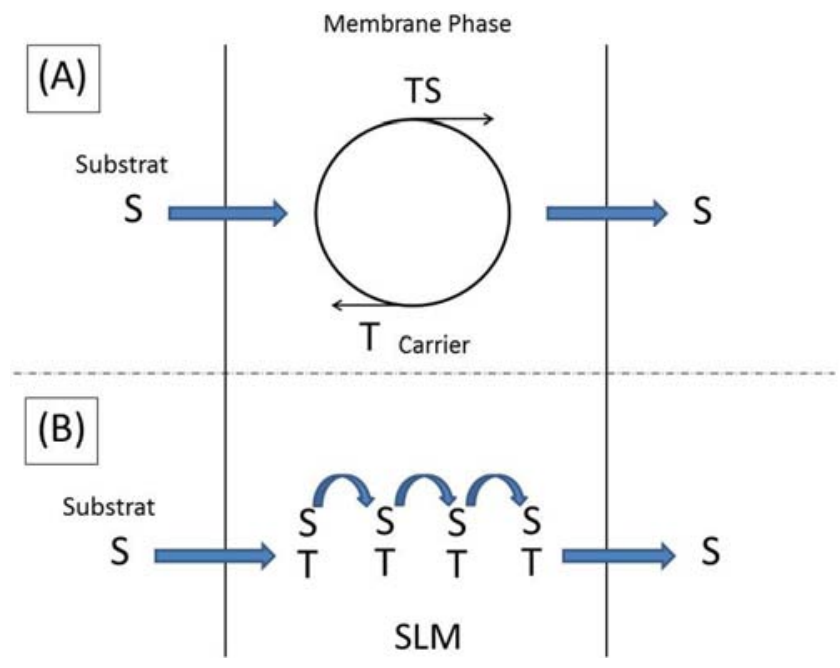

Figure 9. Possible movements of substrate across the organic phases of SLM membranes: (way A); pure diffusion movement (low values of $D^{*}$ ), (way B); movement in successive jumps (high values of $D^{*}$ ). 


\section{Conclusion}

We have developed a new supported liquid membrane containing methyl cholate as extractive agent for the facilitated extraction of a pharmaceutical active ingredient lysine acetylsalicylate from acidic environments. Kinetic and thermodynamic models have been proposed, based on the interaction of the substrate LAS (S) with the MC extractive agent $(\mathrm{T})$, and the diffusion of the formed entity (TS) through the membrane. All experimental results verify the proposed models, which was used to determine the macroscopic parameters permeability $\mathrm{P}$ and initial flux $\mathrm{J}_{0}$ relating to each adopted membranes and the microscopic parameters, association constant $\mathrm{K}_{\mathrm{ass}}$ and apparent diffusion coefficient $\mathrm{D}^{*}$, related to the formation of the entity (ST) and its diffusion through the membrane organic phase. The parameters $\mathrm{K}_{\text {ass }}$ and $\mathrm{D}^{*}$ vary inversely, and the results indicate that very low values of constant $\mathrm{K}_{\text {ass }}$, result in higher values of apparent diffusion coefficients $\mathrm{D}^{*}$, this important result shows that these high values of coefficients $D^{*}$ certainly do not reflect a pure diffusion movement of the entity (ST) through adopted SLMs organic phase. Some recent studies on the facilitated extraction process of organic molecules by the same type of membranes, clearly confirm the high values of the coefficients $D^{*}$, and explain this result by the movement nature of the substrate $S$ during its passage from the feed to the stripping aqueous phases, through the membrane organic phase. On the other hand, studies on the temperature factor influence indicated a clear evolution of all parameters for this phenomenon, and an increase in temperature results in a decrease in the association constant values $\left(\mathrm{K}_{\mathrm{ass}}\right)$, and an increase in parameter values of $\mathrm{D}^{*}, \mathrm{P}$ and $\mathrm{J}_{0}$ and improved performance of the adopted SLMs. The results confirmed the proposed mechanism for this facilitated extraction process, and an increase in the temperature factor disadvantage interactions between substrate $\mathrm{S}$ and the used extractive agent $\mathrm{T}$ ( $\mathrm{K}_{\text {ass }}$ decreases), and facilitates the rapid passage ( $\mathrm{D}^{*}$ increases) of LAS through the membrane organic phase.

\section{Abbreviations}

a slope of the plot $-\ln \left(\mathrm{C}_{0}-2 \mathrm{C}_{\mathrm{r}}\right)=\mathrm{f}(\mathrm{t})$

$\mathrm{C}_{0} \quad$ initial concentration of LAS in the feed phase $\left(\mathrm{mol} \cdot \mathrm{L}^{-1}\right)$

$\mathrm{C}_{\mathrm{r}} \quad$ concentration of LAS ions in the stripping phase $\left(\mathrm{mol} \cdot \mathrm{L}^{-1}\right)$

$\mathrm{C}_{\mathrm{s}} \quad$ concentration of LAS ions in the feed phase

$\mathrm{C}_{\mathrm{s}} \quad\left(\mathrm{mol} \cdot \mathrm{L}^{-1}\right)$

$\mathrm{P} \quad$ the membrane permeability $\left(\mathrm{cm}^{2} \cdot \mathrm{s}^{-1}\right)$

$\mathrm{J}_{0} \quad$ initial flux of LAS $\left(\mathrm{mmol} . \mathrm{cm}^{-2} \cdot \mathrm{s}^{-1}\right)$

D* apparent diffusion coefficient of the complex (TS)

$\left(\mathrm{cm}^{2} \cdot \mathrm{s}^{-1}\right)$

$\mathrm{K}_{\text {ass }} \quad$ association constant of the complex (TS) $\left(\mathrm{L} \cdot \mathrm{mol}^{-1}\right.$ )

1 the membrane thickness ( $\mathrm{mm}$ or $\mu \mathrm{m})$

$\mathrm{S}$ the membrane active area $\left(\mathrm{cm}^{2}\right)$

$[\mathrm{T}]_{0} \quad$ concentration of carrier in the membrane $\left(\mathrm{mol} \cdot \mathrm{L}^{-1}\right)$

$\begin{array}{ll}\mathrm{T} & \text { temperature }(\mathrm{K}) \\ \mathrm{t} & \text { time }(\mathrm{s}) \\ \mathrm{V} & \text { volume of the stripping compartment }\left(\mathrm{cm}^{3}\right)\end{array}$

\section{References}

[1] Park. K and Bavry. A. A, "Aspirin: its risks, benefits, and optimal use in preventing cardiovascular events", Cleveland Clinic Journal of Medicine, vol. 80, no. 5, pp. 318-26. 2013.

[2] Blair. B. D, Crago. J. P, Hedman. C. J and Klaper. R. D, "Pharmaceuticals and personal care products found in the Great Lakes above concentrations of environmental concern," Chemosphere, vol. 93, no. 9, pp. 2116-2123. 2013.

[3] Jiang. M, Yang. W, Zhang. Z, Yang. Z, and Wang. Y, "Adsorption of three pharmaceuticals on two magnetic ionexchange resins," Journal of Environmental Sciences, vol. 31, pp. 226-234, 2015.

[4] Onesios-Barry. K. M, Berry. D, Proescher. J. B, Sivakumar. I. K. A, and Bouwer. E. J, "Removal of Pharmaceuticals and Personal Care Products during Water Recycling: Microbial Community Structure and Effects of Substrate Concentration," Applied and Environmental Microbiology, vol. 80, no. 8, pp. 2440-2450, 2014.

[5] Sadyrbaeva. T. Z, "Removal of chromium(VI) from aqueous solutions using a novel hybrid liquid membraneelectrodialysis process," Chemical Engineering and Processing: Process Intensification, vol. 99, pp. 183-191, 2016.

[6] Soniya. M and Muthuraman. G, "Comparative study between liquid-liquid extraction and bulk liquid membrane for the removal and recovery of methylene blue from wastewater," Journal of Industrial and Engineering Chemistry, vol. 30, pp. 266-273, 2015.

[7] Kocherginsky. N. M, Yang. Q, and Seelam. L, "Recent advances in supported liquid membrane technology," Separation and Purification Technology, vol. 53, no. 2, pp. 171-177, 2007.

[8] Yang. X. J, Fane. A. G and MacNaughton. S, "Removal and recovery of heavy metals from wastewaters by supported liquid membranes", Water Science \& Technology, vol. 42, no. 2, pp. 341-348, 2001.

[9] Mahmoodi. R, T. Mohammadi and Moghadam. M. K. , "Separation of $\mathrm{Cd}(\mathrm{II})$ and $\mathrm{Ni}(\mathrm{II})$ ions by supported liquid membrane using D2EHPA/M2EHPA as mobile carrier", Chemical Papers, vol. 68, no. 6, pp. 751-756, 2013.

[10] Bhatluri. K. K, Manna. M. S, Ghoshal. A. K, and Saha. P, "Supported liquid membrane based removal of lead(II) and cadmium(II) from mixed feed: Conversion to solid waste by precipitation," Journal of Hazardous Materials, vol. 299, pp. 504-512, 2015.

[11] Swain. B, Mishra. C, Jeong. J, Lee. J, Hong. H. S and Pandey. B. D, "Separation of Co(II) and Li(I) with Cyanex 272 using hollow fiber supported liquid membrane: A comparison with flat sheet supported liquid membrane and dispersive solvent extraction process," Chemical Engineering Journal, vol. 271, pp. 61-70, 2015. 
[12] Hao. Z, Vilt. M. E, Wang. Z, Zhang. W, and Winston Ho. W. $\mathrm{S}$, "Supported liquid membranes with feed dispersion for recovery of Cephalexin," Journal of Membrane Science, vol. 468, pp. 423-431, 2014.

[13] Hassoune. H, Rhlalou. T, and Verchère. J-F, "Studies on sugars extraction across a supported liquid membrane: Complexation site of glucose and galactose with methyl cholate," Journal of Membrane Science, vol. 315, no. 1-2, pp. 180-186, 2008.

[14] Pirom. T, Sunsandee. N, Ramakul. P, Pancharoen. U, Nootong. $\mathrm{K}$ and Leepipatpiboon. N, "Separation of amoxicillin using trioctylmethylammonium chloride via a hollow fiber supported liquid membrane: Modeling and experimental investigation," Journal of Industrial and Engineering Chemistry, vol. 23, pp. 109-118, 2015.

[15] Kawasakia. J, Egashiraa. R, Kawaia. T, Haraa. H and Boyadzhiev. L, "Recovery of erythromycin by a liquid membrane", Journal of Membrane Science, vol. 112, no. 2, 17, pp. 209-217, 1996.

[16] Ishizu. H, Habaki. $\mathrm{H}$ and Kawasaki. J, "Permeation and concentration of compactin by a liquid membrane technique", Journal of Membrane Science, vol. 213, no. 1-2, pp. 209-219, 2003.

[17] Kouki. N, Tayeb. R, Zarrougui. R, and Dhahbi. M, "Transport of salicylic acid through supported liquid membrane based on ionic liquids," Separation and Purification Technology, vol. 76, no. 1, pp. 8-14, 2010.

[18] Kamal. O, Benlyamani. A, Serdaoui. F, Riri. M, Cherif. A, and Hlaïbi. M, "Stability Studies of Lysine Acetylsalicylate (Aspirin Derivative): Mechanisms of Hydrolysis," Open Journal of Physical Chemistry, vol. 02, no. 02, pp. 81-87, 2012.

[19] Hlaïbi. M, Tbeur. N, Benjjar. A, Kamal. O and Lebrun. L, "Carbohydrate-resorcinarene complexes involved in the facilitated transport of alditols across a supported liquid membrane", Journal of Membrane Science, vol. 377, no. 1-2, pp. 231-240, 2011.

[20] Fontàs. C, Tayeb. R, Dhahbi. M, Gaudichet. E, Thominette. F, Roy. P, Steenkeste. K, Fontaine-Aupart. M, Tingry. S, TronelPeyroz. E and Seta. P, "Polymer inclusion membranes: The concept of fixed sites membrane revised", Journal of Membrane Science, vol. 290, no. 1-2, pp. 62-72, 2007.

[21] Kislik. S. V, "Principles and Application in Chemical Separations and Wastewater Treatment", Liquid Membranes, pp. $1-15,2010$

[22] Benjjar. A, Eljaddi. T, Kamal. O, Touaj. K, Lebrun. L, and Hlaibi. M, "The development of new supported liquid membranes (SLMs) with agents: Methyl cholate and resorcinarene as carriers for the removal of dichromate ions $\left(\mathrm{Cr}_{2} \mathrm{O}_{7}^{2-}\right)$," Journal of Environmental Chemical Engineering, vol. 2, no. 1, pp. 503-509, 2014.

[23] Konczyk. J, Kozlowski. C, and Walkowiak. W, "Removal of chromium(III) from acidic aqueous solution by polymer inclusion membranes with D2EHPA and Aliquat 336," Desalination, vol. 263, no. 1-3, pp. 211-216, 2010.

[24] Touaj. K, Kamal. O, Atmani. El-H, Eljaddi. T, Lebrun. L and Hlaibi. M, "Membrane processes for the facilitated extraction of disaccharide sugars: Parameters and mechanism", Microporous and Mesoporous Materials, vol. 198, 2014, pp. 122-128.

[25] Hor. M, Riad. A, Benjjar. A, Lebrun. L, and Hlaïbi. M, "Technique of supported liquid membranes (SLMs) for the facilitated transport of vanadium ions $\left(\mathrm{VO}_{2}^{+}\right)$," Desalination, vol. 255 , no. $1-3$, pp. 188-195, 2010.

[26] Benjjar. A, Hor. M, Riri. M, Eljaddi. T, Kamal. O, Lebrun. L, and Hlaïbi. M, "A new supported liquid membrane (SLM) with methyl cholate for facilitated transport of dichromate ions from mineral acids: parameters and mechanism relating to the transport.", Journal of Materials and Environmental Science, vol. 3, no. 5, pp. 826-839, 2012. 